\title{
Equivalência de itens, semântica e operacional da "Escala de Musicabilidade: Formas de Atividade, Estágios e Qualidades de Engajamento"
}

\section{Item, semantic and operational equivalence of the "Musicing: Forms of Activity, Stages and Qualities of Engagement Scale"}

Aline Moreira Brandão André Universidade Federal de Minas Gerais aline.musicasax@gmail.com

Cristiano Mauro Assis Gomes ${ }^{2}$ Universidade Federal de Minas Gerais cristianomaurogomes@gmail.com

Cybelle Maria Veiga Loureiro 3 Universidade Federal de Minas Gerais cybelleveigaloureiro@gmail.com

Submetido em 25/05/2020 Aprovado em 09/09/2020

\footnotetext{
Aline M. B. André é doutoranda em Música na Universidade Federal de Minas Gerais, tem mestrado em Música (2017) e bacharelado em Música - Musicoterapia pela Universidade Federal de Minas Gerais (2014). Participou de pesquisas nos seguintes temas: protocolo de atendimento, transtorno do espectro do autismo, patologias neurológicas, musicoterapia improvisacional, musicoterapia neurológica e Escalas Nordoff Robbins.

${ }^{2}$ Cristiano M. A. Gomes tem doutorado em Educação - UFMG, Pós-Doutorado em Psicologia Educacional, Universidade do Minho, Portugal. É Professor do Departamento de Psicologia da UFMG, Professor do Programa de Pós-Graduação em Psicologia (UFMG e do Programa de Pós-Graduação em Neurociências (UFMG). Coordenador do Laboratório de Investigação da Arquitetura Cognitiva (LAICO). Bolsista de Produtividade nível 2, CNPq.

${ }^{3}$ Cybelle M. V. Loureiro tem bacharelado em Música; Graduação em Musicoterapia - lowa University-EUA; Mestrado em Música -EM-UFMG; Doutorado em Medicina - FM-UFMG e é Coordenadora da Habilitação-Musicoterapia ESMU-UFMG, Professora da Pós-graduação em Música da ESMU-UFMG e Neurociências - ICB-UFMG.
} 


\section{Resumo}

Na década de 1960, os pesquisadores Nordoff e Robbins começaram a desenvolver escalas para avaliação em atendimentos musicoterapêuticos. Dentre elas, a "Escala de Musicabilidade: Formas de Atividade, Estágios e Qualidades de Engajamento". Esta escala foi desenvolvida para avaliar as "sutilezas" presentes na produção musical de um paciente em um atendimento musicoterapêutico. No Brasil, é grande a necessidade de instrumentos de medida validados para nosso idioma. A fim de contribuir com a validação no contexto musicoterapêutico brasileiro, objetivamos avaliar a tradução desta escala e seu respectivo manual explicativo. Como metodologia, realizamos 3 etapas do Modelo Universalista de Validação desenvolvido por Herdman, Fox-Hushby e Badia (1998) denominadas equivalência de itens, equivalência semântica e equivalência operacional. Participaram desse estudo 6 tradutores na etapa inicial e 9 avaliadores no processo de avaliação da tradução. Foram utilizados como instrumentos, a "Escala de Musicabilidade: Formas de Atividade, Estágios e Qualidades de Engajamento" e seu respectivo manual explicativo. Foi elaborada para este estudo uma Ficha para análise das traduções e um Questionário de Análise da Equivalência de Itens, Semântica e Operacional. De acordo com a análise das respostas coletadas dos avaliadores, a tradução dessa escala apresenta linguagem compreensível, seus itens são pertinentes para o contexto brasileiro e podem contribuir para futuras pesquisas em musicoterapia e em música.

Palavras-chave: Escala de Musicabilidade: Formas de Atividade, Estágios e Qualidades de Engajamento; Musicoterapia; Tradução.

\section{Abstract}

In the 1960s, the researchers Nordoff and Robbins started develop scales in order to assess music therapy services. Among them the "Musicing: Forms of Activity, Stages and Qualities of Engagement Scale". This scale was developed to evaluate subtleties present in the musical production from a patient taking part on music therapy service. In Brazil, there is a great demand for validated measurement instruments in Brazilian language. In order to contribute to the validation in the Brazilian music therapy context, this work aims to evaluate the translation of this scale and its respective explanatory manual. As a methodology, we performed 3 steps from the Universalist Validation Model developed by Herdman, Fox-Hushby and Badia (1998), named item equivalence, semantic equivalence and operational equivalence. Six translators participated in this study in the initial stage and 9 evaluators in the translation perused the process. "Musicing: Forms of Activity, Stages and Qualities of Engagement Scale" and its respective explanatory manual were used as instruments. For this study, a Form for the analysis of the Translations and a Questionnaire for Analysis of the Items, Semantics and Operational Equivalences were prepared. According to the analysis of the responses collected from the evaluators, the translation of this scale has understandable language, their items are relevant to the Brazilian context and may contribute to future research in music and music therapy.

Keywords: Field recording; listening; urban walks; negative spaces; opaque spaces. 


\section{Introdução}

Desde seu surgimento, a Musicoterapia tem se consolidado como uma profissão multidisciplinar que transita nas áreas da música, da pesquisa, da educação e da saúde. Diversos autores como Baker e Roth (2004), Barcellos (1992), Bruscia (2000), Loureiro (2006; 2009), Thaut e Hoemberg (2014) e Wheeler (2015), descrevem os efeitos positivos da prática musicoterapêutica em várias faixas etárias e condições de saúde. Em conjunto com o crescimento da profissão, começaram a ser desenvolvidos modos de avaliar o paciente e o desenvolvimento clínico. Inicialmente, grande parte dos meios de avaliação consistiam em relatórios descritivos considerando o que ocorria nas sessões. Contudo, com o passar dos anos foram desenvolvidos instrumentos de avaliação capazes de proporcionar uma avaliação mais objetiva e algum tipo de análise estatística. Atualmente, estudos têm realizado uma análise detalhada de dados extraídos de uma única experiência com um paciente ou de uma sessão de Musicoterapia (WOSCH; WIGRAM, 2007).

Zmitrowiczab e Moura (2018), ao realizarem um estudo de revisão sobre os instrumentos de avaliação existentes em Musicoterapia, descreveram que encontraram ao todo 55 instrumentos, mas somente 9 destes foram estudados no contexto brasileiro. Atualmente no Brasil, mais duas pesquisas de validação foram concluídas (FREIRE, 2019; ROSÁRIO, 2019) e uma está em andamento (FERREIRA; TUPINÁ; LOUREIRO, 2018). Diversos autores como Gattino (2012), Rosário (2019), Sampaio (2015), Silva (2012) e Zmitrowiczab e Moura (2018) afirmam que existe uma necessidade de validação de mais instrumentos de avaliação em Musicoterapia no contexto brasileiro, considerando que a avaliação é um processo fundamental da prática clínica na qual o terapeuta deve observar o paciente em experiências musicais para identificar problemas clínicos, problemas emocionais, expectativas, anseios, entre outras questões.

Em nosso atual estudo pretendemos contribuir para a validação de instrumentos de avaliação no contexto musicoterapêutico do Brasil traduzindo para o português brasileiro uma escala desenvolvida a partir de estudos que se iniciaram na década de 1960 nos Estados Unidos denominada "Escala de Musicabilidade: Formas de Atividade, Estágios e Qualidades de Engajamento".

Nordoff e Robbins (2007) relatam que desenvolveram 3 escalas através de pesquisas realizadas na Universidade da Pensilvânia. Inicialmente elas foram elaboradas para avaliação de crianças com autismo, mas posteriormente foram atualizadas e passaram a ser utilizadas para avaliação de pessoas com diversas condições. A primeira escala desenvolvida é denominada "Escala de Relação Criança Terapeuta na Experiência Musical Coativa" (The Child-Therapist Relationship in Coactive Musical Experience). Essa escala está sendo estudada para fins de validação no contexto brasileiro por André, Gomes e Loureiro (2019). A segunda escala tem o nome de "Escala de Comunicabilidade Musical" (Musical Communicativeness). A mesma foi traduzida e validada para o contexto brasileiro em uma pesquisa de mestrado realizada por André (2017). A terceira escala, foco de nosso estudo atual, é denominada "Escala de Musicabilidade: Formas de Atividade, Estágios e Qualidades de Engajamento" (Musicing: Forms Of Activity, Stages And Qualities Of Engagement). 
André, Gomes e Loureiro (2020), ao realizarem uma revisão sobre a "Escala de Musicabilidade: Formas de Atividade, Estágios e Qualidades de Engajamento", descrevem que a mesma tem sido utilizada para avaliar pessoas com Transtorno do Espectro Autista (TEA) e demais condições médicas (AMERICAN PSYCHIATRIC ASSOCIATION, 2014). Além disso, esta escala ela é citada em diversas publicações em inglês (CRIPPS; TSIRIS; SPIRO, 2016; NORDOFF; ROBBINS, 2007; SPIRO; TSIRIS; CRIPPS, 2017; CARPENTE; AIGEN, 2019) e em português (ANDRÉ, 2017; ANDRÉ; GOMES; LOUREIRO, 2016, 2017, 2019; SILVA, 2017; ZMITROWICZAB; MOURA, 2018).

A “Escala de Musicabilidade: Formas de Atividade, Estágios e Qualidades de Engajamento" foi desenvolvida para avaliar as "sutilezas" presentes na produção musical de um paciente em um atendimento musicoterapêutico. Nordoff e Robbins (2007) afirmam que nessa escala, cada classificação de uma resposta combina diretamente o registro do nível de complexidade de sua forma musical com uma avaliação do estágio ou qualidade do engajamento expresso nela. Em outras palavras, o que uma criança faz musicalmente é avaliado junto com a forma como ela o faz. Por isso, nessa escala é avaliado a variação de batida que um paciente faz em um instrumento, as formas rítmicas que o mesmo utilizou, os componentes expressivos e a forma melódica com que vocalizou.

Segundo os autores Nordoff e Robbins (2007) a "Escala de Musicabilidade: Formas de Atividade, Estágios e Qualidades de Engajamento" foi elaborada considerando a diversidade da interatividade musical criança-terapeuta na musicoterapia improvisacional. Perceberam, com o tempo, que essa diversidade exigia um instrumento de avaliação capaz de abranger um amplo escopo da atividade musical e da relação funcional do comportamento. Além disso, eles afirmam que as complexidades e sutilezas das respostas das crianças necessitam de um instrumento de avaliação sensível e que tivesse graduações, como por exemplo as alterações de batimentos por minuto (bpm) visto na escala. Os autores relatam que as duas principais categorias nas quais as respostas musicais de uma criança em terapia ocorrem são: atividade rítmica instrumental e canto. Segundo eles, em nenhuma delas o significado clínico de uma resposta pode ser determinado apenas pelo seu caráter estrutural. O grau de ativação ou engajamento expresso nela deve ser reconhecido como tendo pelo menos igual importância. Todas as respostas musicais são multidimensionais. A própria música tem suas principais dimensões de estrutura e expressão. A sua dimensão estrutural subdivide-se nos componentes da batida básica, ritmo, forma rítmica e complexidade melódica; sua dimensão expressiva se manifesta em seus vários componentes expressivos, como o accelerando, fermata, diminuendo, rubato, etc. Dentro dessas dimensões da música, a resposta de cada criança assume suas próprias dimensões pessoais. Para os autores, dependendo do caráter da atividade musical, uma gama de processos psicológicos e físicos podem ser ativados como: "consciência, percepção, atenção, ideação, concentração, memória, desenvolvimento da coordenação e flexibilidade corporal ou vocal, responsividade emocional, diferenciação emocional, integração receptivo-expressiva, intencionalidade e autoexpressão". Individualmente e variadamente, esses processos se combinam em resposta musical e, portanto, devem ser considerados na avaliação de sua significância clínica. 
Este artigo tem como objetivo apresentar a tradução da "Escala de Musicabilidade: Formas de Atividade, Estágios e Qualidades de Engajamento", realizando também as equivalências de itens, semântica e operacional da mesma para o contexto brasileiro. O mesmo é parte integrante de uma pesquisa realizada no Programa de Pós-Graduação em Música da Universidade Federal de Minas Gerais. Este projeto foi registrado no Comitê de Ética e Pesquisa da universidade sob o número 04167218.2.0000.5149. Adotamos como metodologia para verificação de indícios de validade desta escala para o contexto brasileiro, o Modelo Universalista de Validação apresentado por Herdman, Fox-RushbY e Badia (1998) que prevê a verificação de seis equivalências: conceitual, de itens, semântica, operacional, de mensuração e funcional.

\section{Metodologia:}

Participantes. Fizeram parte desse estudo 6 tradutores e 9 avaliadores.

Todos os tradutores têm experiência em pesquisa e conhecimento de inglês e português. Dentre eles, 2 têm formação em Letras, 2 têm formação em música e 2 têm formação em Musicoterapia. Com relação ao gênero, 4 são do sexo feminino e 2 são do sexo masculino.

Os 9 avaliadores são musicoterapeutas que possuem prática de pesquisa e experiência clínica. O tempo de experiência clínica entre eles varia entre 2 a 25 anos. Com relação ao gênero, 7 avaliadores são do sexo feminino e 3 são do sexo masculino.

Instrumentos. Foram elaborados para este estudo dois instrumentos: um para análise das traduções e outro para análise semântica dos itens e do formato de apresentação da escala. São eles: a ficha para análise das traduções e um questionário aplicado aos avaliadores. Tais instrumentos foram desenvolvidos com base nos questionários utilizados para avaliação das equivalências de itens, semântica e operacional da "Escala de Comunicabilidade Musical", descritos nos estudos de André (2017) e André; Gomes e Loureiro (2017). Acreditamos que uma pesquisa que mantém a mesma metodologia nos possibilitou ter o mesmo rigor científico nos resultados para as duas escalas no contexto brasileiro.

Além desses instrumentos, também utilizamos a "Escala de Musicabilidade: Formas de Atividade, Estágios e Qualidades de Engajamento" em inglês e o manual explicativo original desta escala com seus respectivos áudios. A escala e o manual podem ser encontrados no capítulo 18 do livro Creative Music Therapy: Guide to Fostering Clinical Musicianship, escrito pelos autores Nordoff, e Robbins (2007). Juntamente com o manual, também podem ser encontrados áudios complementares ao texto. Esses áudios são exemplos clínicos da aplicação da escala e contêm trechos de atendimentos musicoterapêuticos.

A fim de facilitar a verificação das traducões, desenvolvemos uma ficha de análise. Nela estão descritas cinco questões discursivas que permitem que o tradutor ava- 
liador opine sobre as traduções e possíveis modificações para melhor entendimento do texto (Tab. 1).

Ficha para Análise das Traduções

1- Ao ler o texto original, a tradução para o português e a retradução para o inglês, você considera que os três textos apresentam os mesmos conceitos e conteúdos semanticamente? Justifique sua resposta.

2- Existe algum trecho que poderia ser melhor explicado em português para maior entendimento da Escala? Justifique sua resposta.

3- Você sugere a troca de alguma palavra no texto ou na "Escala de Musicabilidade: Formas de Atividade, Estágios e Qualidades de Engajamento"?

4- De 0 a 10, como você avaliaria a tradução e a versão em português do texto e da "Escala de Musicabilidade: Formas de Atividade, Estágios e Qualidades de Engajamento"? Justifique sua resposta.

5- Você considera que algumas partes do texto devem ser retiradas quando o capítulo for divulgado e publicado?

Tab. 1: Ficha para Análise das Traduções contendo 5 questões descritivas para arguições.

O Questionário de Análise para Equivalências de Itens, Semântica e Operacional aplicado aos avaliadores foi elaborado com 14 questões de múltipla escolha. Abaixo de cada uma das questões, o examinador tinha a possibilidade de justificar sua resposta (Tab. 2).

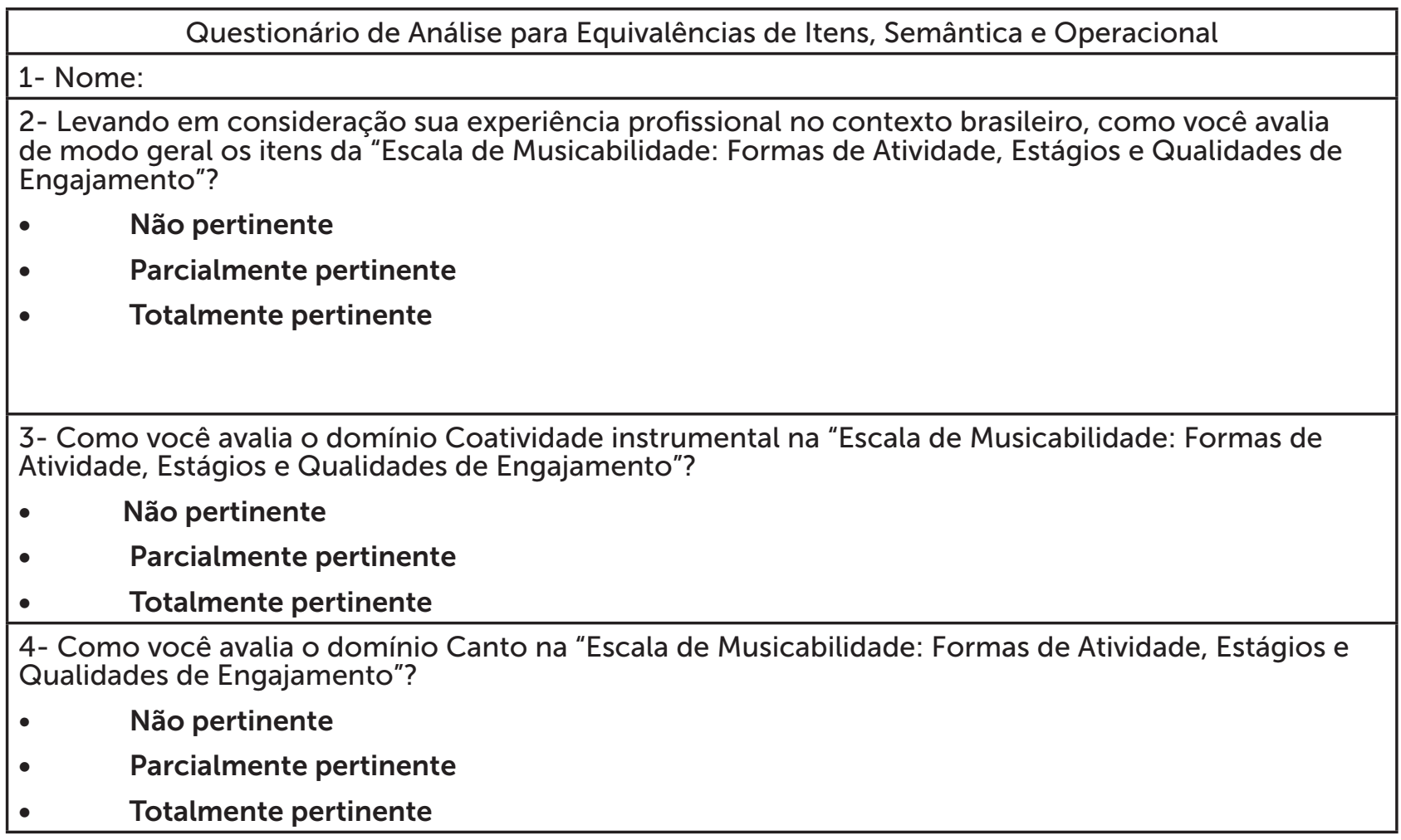




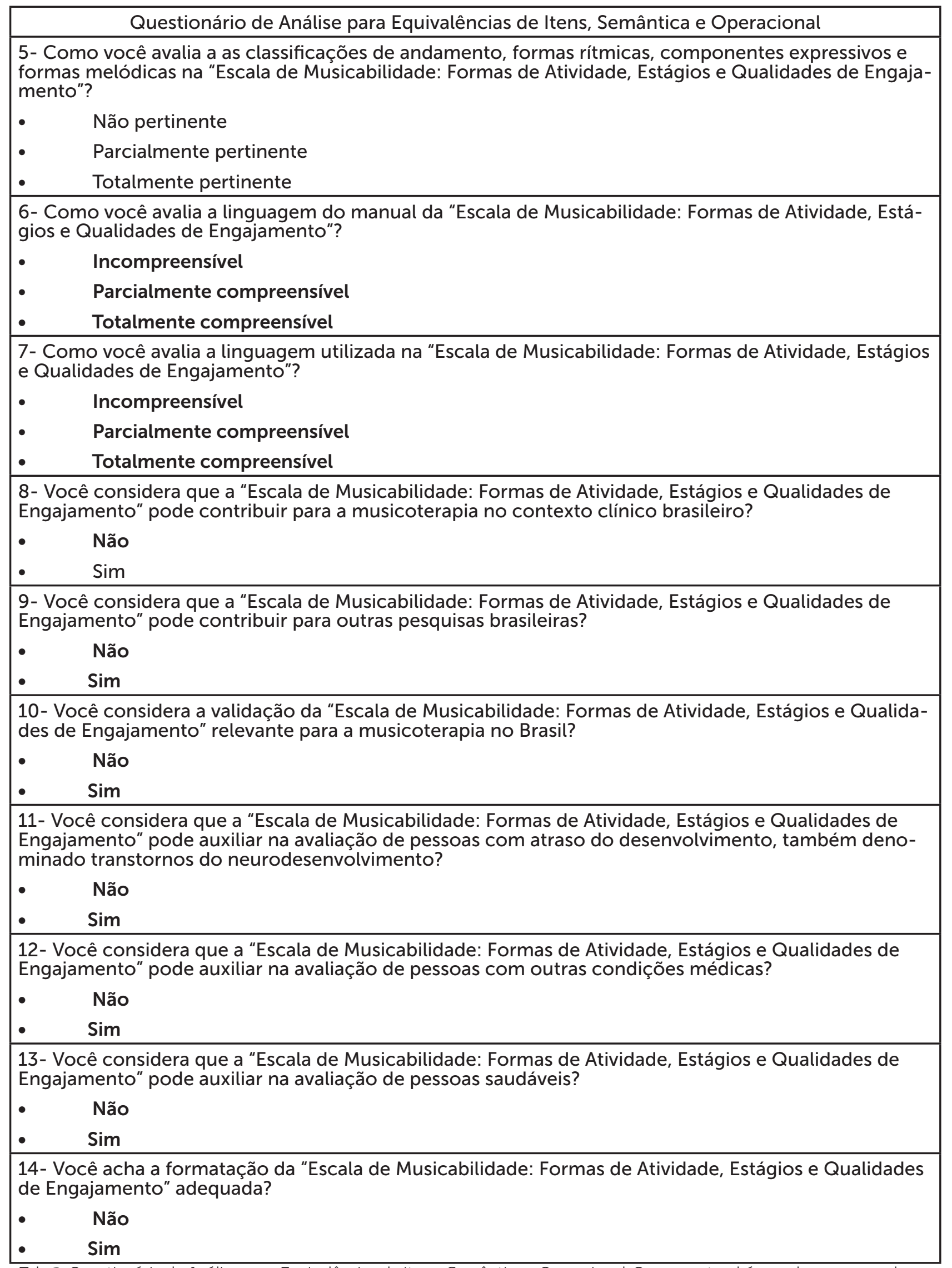

Tab. 2: Questionário de Análise para Equivalências de Itens, Semântica e Operacional. O mesmo também pode ser acessado no seguinte link: https://docs.google.com/forms/d/e/1FAlpQLSfAVrWX2Gg-6h9HxWfvxvQktYtpCY3bFeRmY-EgUAd4Csh5Hg/view- 
Coleta de dados. A coleta de dados ocorreu a partir da tradução da "Escala de Musicabilidade: Formas de Atividade, Estágios e Qualidades de Engajamento" em conjunto com seu manual explicativo e aplicação de questionários.

O processo de tradução da "Escala de Musicabilidade: Formas de Atividade, Estágios e Qualidades de Engajamento" ocorreu por pares e em 3 etapas. A primeira etapa consistiu em traduzir o manual e a escala do inglês para o português. Nessa etapa, participaram 2 tradutores. Na segunda etapa ocorreu a retradução do texto em português para o inglês por outros 2 tradutores. Os tradutores convidados para a segunda etapa não tiveram acesso à versão original do texto. Finalmente na terceira etapa, outros 2 tradutores foram convidados para analisar e comparar o texto original, a versão em português e a retradução para o inglês com a finalidade de avaliar, de forma imparcial, se o texto apresentava as mesmas informações e se precisava ou não de modificações na escrita. Uma ficha para análise foi entregue aos tradutores da terceira etapa para que os mesmos justificassem sua opinião referente à avaliação dos textos.

Posteriormente ao processo de tradução, 9 avaliadores foram convidados a ler o texto e preencher um questionário com 14 questões para avaliar a semântica, a relevância dos itens da "Escala de Musicabilidade: Formas de Atividade, Estágios e Qualidades de Engajamento" para o contexto brasileiro e o melhor formato de apresentação da mesma. O questionário foi elaborado na plataforma Google e foi enviado por e-mail aos avaliadores.

Análise de dados. As traduções foram analisadas a partir das comparações com o texto original. Após avaliar as traduções, uma versão em português foi analisada pelos avaliadores para verificar a semântica, os itens e o melhor formato de apresentação da escala. Os dados dos tradutores e avaliadores foram armazenados na planilha eletrônica Microsoft Excel 2019. Ao analisar estes dados, de acordo com o Modelo Universalista de Validação desenvolvido por Herdman, Fox-Hushby e Badia (1998), foi possível investigar as equivalências de itens, semântica e operacional da "Escala de Musicabilidade: Formas de Atividade, Estágios e Qualidades de Engajamento". As investigações sobre as equivalências realizadas neste estudo, com base no Modelo Universalista de Validação, podem ser melhor explicadas da seguinte forma:

Equivalência semântica: Consistiu na avaliação da linguagem utilizada levando em consideração as adaptações culturais. Nessa etapa, foi verificado se a palavra utilizada para tradução definia o melhor significado ou se deveria ser substituída por outra palavra para maior interpretação da escala.

Equivalência de itens: Consistiu na análise pelos avaliadores, da pertinência de cada item da escala, levando em consideração as diferenças culturais.

Equivalência operacional: Consistiu na análise dos avaliadores sobre qual seria o melhor formato para apresentação da "Escala de Musicabilidade: Formas de Atividade, Estágios e Qualidades de Engajamento". 


\section{Resultados}

Após verificação de cada texto traduzido, não foi encontrada nenhuma falha que alterasse o sentido original da "Escala de Musicabilidade: Formas de Atividade, Estágios e Qualidades de Engajamento" e de seu respectivo manual. Os colaboradores responsáveis pela avaliação das traduções deram nota 9 para as mesmas. Segundo eles, algumas palavras poderiam gerar certa confusão na versão em português devido a escolha de palavras na frase original em inglês. Os mesmos descreveram que no texto original, os autores usam repetidas vezes a palavra "it" na mesma frase. Como essa é uma palavra usada para vários contextos, dificulta a tradução para o português porque parece complexo entender em alguns trechos o que o autor queria realmente descrever com essa palavra, sem precisar perguntar pessoalmente ao mesmo. Os tradutores sugeriram que o texto fosse lido por diversos musicoterapeutas para que os mesmos identificassemo que consideram adequado para o contexto musicoterapêutico brasileiro

De um modo geral, a tradução foi considerada bem elaborada. Com relação a Escala em si, o texto foi considerado adequado para o contexto brasileiro. As três versões, original, traduzida para o português e retraduzida para o inglês da "Escala de Musicabilidade: Formas de Atividade, Estágios e Qualidades de Engajamento", foram dispostas em um quadro para melhor visualização (Tab. 3).

Comparação entre versão original, tradução e retradução da "Escala de Musicabilidade: Formas de Atividade, Estágios e Qualidades de Engajamento"

\begin{tabular}{|c|c|c|c|}
\hline & Original & Traduzido & Retraduzido \\
\hline Título & $\begin{array}{l}\text { Musicing: Forms of Ac- } \\
\text { tivity, Stages and Quali- } \\
\text { ties of Engagement }\end{array}$ & $\begin{array}{l}\text { Musicabilidade: Formas } \\
\text { de Atividade, Estágios e } \\
\text { Qualidades de Engaja- } \\
\text { mento }\end{array}$ & $\begin{array}{l}\text { Musicability: forms of } \\
\text { activity, stages and qua- } \\
\text { lities of engagement }\end{array}$ \\
\hline Domínio & Instrumental Coactivity & $\begin{array}{l}\text { Coatividade instrumen- } \\
\text { tal }\end{array}$ & Instrumental coactivity \\
\hline \multirow[t]{6}{*}{1} & $\begin{array}{l}\text { (1) Basic beat tempo } \\
\text { range }\end{array}$ & $\begin{array}{l}\text { (1) Batida básica } \\
\text { Variação do andamento }\end{array}$ & $\begin{array}{l}\text { Basic beat } \\
\text { Variation in tempo }\end{array}$ \\
\hline & Very fast 240 & Muito rápido 240 & Very fast 240 \\
\hline & Fast 150 & Rápido 150 & Fast 150 \\
\hline & Moderate 95 & Moderado 95 & Moderate 95 \\
\hline & Slow 60 & Lento 60 & Slow 60 \\
\hline & Very slow & Muito lento & Very slow \\
\hline \multirow[t]{6}{*}{2} & (2) Rhythmic forms & Formas rítmicas & Rhythmic forms \\
\hline & Complex & Complexo & Complex \\
\hline & Advenced & Avançado & Advenced \\
\hline & Intermediate & Intermediário & Intermediate \\
\hline & Simple & Simples & Simple \\
\hline & Rudimentary & Rudimentar & Rudimentary \\
\hline
\end{tabular}




\begin{tabular}{|c|c|c|c|}
\hline \multirow[t]{3}{*}{3} & $\begin{array}{l}\text { (3) Expresive Com- } \\
\text { ponents }\end{array}$ & $\begin{array}{l}\text { Componentes expres- } \\
\text { sivos }\end{array}$ & Expresive Components \\
\hline & Tremolo & Trêmulo & Tremolo \\
\hline & Dynamic contrast & Contraste Dinâmico & Dynamic contrast \\
\hline & P/Dim & P/Dim & P/Dim \\
\hline & Accent Punctuation & Acento Pontuação & Accent Punctuation \\
\hline & P/Cres & F/Cresc & F/Cresc \\
\hline & Sound of instrument & Som do Instrumento & Sound of instrument \\
\hline & Accel & Accel & Accel \\
\hline & Rit & Rit & Rit \\
\hline & Tempo contrast & $\begin{array}{l}\text { Contraste do andamen- } \\
\text { to }\end{array}$ & Contrast of tempo \\
\hline & Fermata & Fermata & Fermata \\
\hline & Rubato & Rubato & Rubato \\
\hline \multirow[t]{9}{*}{4} & Singing & Canto & Singing \\
\hline & Melodic form & Forma melódica & Melodic form \\
\hline & & $\begin{array}{l}\text { Improvisação parecida } \\
\text { com uma ária }\end{array}$ & \\
\hline & Aria-like improvising & $\begin{array}{l}\text { Improvisação parecida } \\
\text { com uma ária }\end{array}$ & Aria-like improvising \\
\hline & Complex Melodies & Melodias complexas & Complex Melodies \\
\hline & Simple Melodies & Melodias simples & Simple Melodies \\
\hline & Melodic Phrases & Frases melódicas & Melodic Phrases \\
\hline & Simple Tonal Forms & Formas tonais simples & Simple tonal shapes \\
\hline & T/R related sounds & Sons Relacionados T/R & Related T / R Sounds \\
\hline
\end{tabular}

Tab. 3: Comparação entre versão original, tradução e retradução da "Escala de Musicabilidade: Formas de Atividade, Estágios e Qualidades de Engajamento".

Com relação aos dados provenientes do questionário aplicado aos 9 musicoterapeutas avaliadores, referente à análise das equivalências de itens, semântica e operacional da "Escala de Musicabilidade: Formas de Atividade, Estágios e Qualidades de Engajamento", também encontramos resultados satisfatórios.

Na questão 1 foram perguntados os nomes dos avaliadores.

Na questão 2, ao serem perguntados sobre como avaliavam os itens presentes na escala para o contexto brasileiro, 5 avaliadores $(55,6 \%)$ consideraram totalmente pertinente, 3 avaliadores (33,3\%) consideraram parcialmente pertinente e 1 avaliador $(11,1 \%)$ considerou não pertinente. Os avaliadores que consideraram os itens totalmente pertinentes relataram que na opinião deles os itens da escala descrevem com detalhes as importantes observações que o musicoterapeuta pode ter sobre a expressão musical e a musicalidade da criança. Segundo eles, a escala consegue abranger as diferentes formas de expressão vistas em atendimentos musicoterapêuticos corriqueiros. Os avaliadores que consideraram a escala parcialmente pertinente relataram que, em sua 
opinião, os itens da escala são bastante complexos, havendo a necessidade de uma formação complementar e específica para que o musicoterapeuta possa aplicá-los. 0 que considerou os itens da escala não pertinente relatou que no Brasil nem todos os consultórios musicoterapêuticos possuem piano e diversos instrumentos para facilitar a utilização da escala e além disso, a formação musical do musicoterapeuta pode variar dependendo de onde estudou.

Na questão 3, ao serem perguntados como avaliam o domínio Coatividade instrumental na "Escala de Musicabilidade: Formas de Atividade, Estágios e Qualidades de Engajamento", 5 avaliadores (55.6\%) consideraram totalmente pertinente e 4 avaliadores $(44,4 \%)$ consideraram parcialmente pertinente. Os que consideraram totalmente pertinente relataram que através desse domínio seria possível identificar em qual estágio da terapia o paciente está e quais são as dificuldades tanto cognitivas quanto motoras do mesmo, o que permite estabelecer novos objetivos ou permanecer com os mesmos a partir da descrição de como o paciente se encontra. Os que consideraram parcialmente pertinente relataram que alguns subníveis desse domínio são interessantes, como a forma de analisar os componentes na estrutura rítmica e dos componentes expressivos mas acreditam que as subclassificações desses domínios não são muito fáceis de entender.

Na questão 4, quando perguntados sobre o domínio Canto na "Escala de Musicabilidade: Formas de Atividade, Estágios e Qualidades de Engajamento", 7 avaliadores $(77,8 \%)$ consideraram totalmente pertinente, 1 avaliador $(11,1 \%)$ considerou parcialmente pertinente e 1 avaliador (11,1\%) considerou não pertinente. Os que consideraram totalmente pertinente acreditam que é possível perceber com a prática clínica que as formas melódicas e o canto, gradualmente, tendem a alcançar formas mais elaboradas e complexas de expressão e habilidade. Os avaliadores acreditam que a graduação dos níveis das formas melódicas compatível à prática clínica juntamente com o ato de definir e graduar estes aspectos é fundamental para que a classe musicoterapêutica tenha acesso à um instrumento de avaliação contundente, objetivo e padronizado. Além disso, segundo eles. através do canto é possível identificar como se encontrar a criança pois, de acordo com o engajamento da criança no canto, seja ele espontâneo ou estimulado, é possível identificar como a criança se encontra dentro da sessão, principalmente no contexto emocional, mas também nos contextos físico e mental. $\mathrm{O}$ avaliador que considerou o domínio canto parcialmente pertinente acredita que uma classificação em 3 níveis: básico, intermediário e elaborado poderia funcionar melhor. $\mathrm{O}$ avaliador que considerou esse domínio não pertinente acredita que alguns subníveis seriam desnecessários, tais como verificar se a criança cantou um trecho de uma ária, pois, para realizar esse tipo de identificação, é necessário que o musicoterapeuta saiba bem classificar esses conceitos da linguagem técnica musical erudita, uma vez que as árias não são todas iguais.

$\mathrm{Na}$ questão 5, quando perguntados sobre as classificações de andamento, formas rítmicas, componentes expressivos e formas melódicas na "Escala de Musicabilidade: Formas de Atividade, Estágios e Qualidades de Engajamento", 6 avaliadores (66,7\%) consideraram totalmente pertinente e 3 avaliadores $(33,3 \%)$ consideraram parcialmente 
pertinente. Os avaliadores que consideraram essas classificações totalmente pertinentes relataram que é extremamente importante que se tenha classificações de cada aspecto avaliado para que haja detalhamento, esclarecimento e padronização dos componentes avaliados característicos das dimensões estruturais e expressivas, além daqueles que permeiam as formas melódicas e o canto, em seus níveis de desenvolvimento expressivo e de habilidade. Além disso, considerando que se leva em conta as dificuldades individuais de cada criança, e que mesmo ela não realizando a atividade proposta pelo musicoterapeuta como o esperado, o comportamento dela é avaliado. Ainda segundo os avaliadores, a descrição seguindo uma sequência gradativa torna fácil a avaliação e é interessante inclusive para uma avaliação comparativa do paciente com ele mesmo no futuro. Os avaliadores que consideraram essa classificação parcialmente pertinente relataram que as classificações são muito detalhadas, sendo difíceis de serem avaliadas. Segundo eles, talvez as classificações rudimentar e simples ou avançada e complexa poderiam ser agrupadas para facilitar a avaliação.

Na questão 6, quando perguntados sobre a linguagem do manual da "Escala de Musicabilidade: Formas de Atividade, Estágios e Qualidades de Engajamento", 4 avaliadores $(44,4 \%)$ consideraram totalmente compreensível e 5 avaliadores $(55,6 \%)$ consideraram parcialmente compreensível. Os que consideraram totalmente compreensível relataram que o manual está muito bem escrito, com termos claros, de fácil entendimento e com ótimas descrições e exemplos. Os que consideraram parcialmente compreensível relataram que a escala é bem especifica em muitas etapas para musicoterapeutas e também pode ser considerada relevante para outros profissionais da música. Contudo, em alguns trechos a leitura fica densa e alguns termos podem não ser compreensíveis e não ter relevância para outras terapias. Segundo eles, poderia ser utilizada uma linguagem mais clara.

Na questão 7, ao serem perguntados sobre a linguagem utilizada na "Escala de Musicabilidade: Formas de Atividade, Estágios e Qualidades de Engajamento", 7 avaliadores $(77,8 \%)$ consideraram totalmente compreensível e 2 avaliadores $(22,2 \%)$ consideraram parcialmente compreensível. Segundo os avaliadores que consideraram a linguagem totalmente compreensível, a escala apresenta de forma objetiva todos os componentes avaliados, sejam eles expressivos, estruturais ou do canto e forma melódica. Segundo os avaliadores que consideraram a escala parcialmente compreensível, as abreviaturas, especialmente nos componentes expressivos, podem dificultar no preenchimento dos dados na hora da avaliação. Segundo eles, seria melhor utilizar as palavras sem as abreviaturas sugeridas pelos autores.

Nas questões de 8 a 10, quando perguntados se a "Escala de Musicabilidade: Formas de Atividade, Estágios e Qualidades de Engajamento" pode contribuir para a musicoterapia no contexto clínico, na prática de pesquisa e se há relevância da mesma no contexto geral brasileiro, todos os avaliadores relataram que sim. Eles descreveram que no atual cenário da Musicoterapia nacional todos os esforços são válidos para que a profissão ganhe o seu lugar de merecimento. Produções importantes como estas demonstram o quanto a profissão é complexa, importante e como pode ser de grande utilidade no tratamento das mais diversas síndromes e patologias existentes. A Escala é 
um instrumento específico de avaliação, considerando aspectos musicais das respostas dadas pela criança, além do estágio e qualidade de engajamento expresso por ela. Do ponto de vista científico, as escalas e estudos específicos, aumentam a credibilidade de prática e campo do saber, possibilita desdobramentos de outras pesquisas e a aplicabilidade na clínica musicoterapêutica, além de maior valorização, congruência e diferenciação do profissional musicoterapeuta. Ainda segundo os avaliadores, esta escala ajuda o musicoterapeuta (e ajudará inclusive o musicoterapeuta brasileiro) a observar nuances musicais do paciente, importantes na experiência musical em Musicoterapia e que são difíceis de se observar em outras escalas.

Nas questões de 11 a 13, quando perguntados se a "Escala de Musicabilidade: Formas de Atividade, Estágios e Qualidades de Engajamento" pode auxiliar na avaliação de pessoas com transtornos do neurodesenvolvimento, pessoas saudáveis ou pessoas com outras condições médicas, todos os avaliadores responderam que sim. Segundo eles, a atividade musical nos Transtornos do Neurodesenvolvimento também se dá através de respostas musicais e do canto, com componentes expressivos, estágios e engajamento particulares. Com isso, a escala em questão poderia auxiliar na avaliação desta população também. Além disso, tornando como base as respostas que possam ser consideradas como esperadas para cada idade ou condição, a escala pode ser utilizada como meio de verificação e apontamento de condições médicas pois, todos os domínios são observados em todas as atividades propostas para as pessoas em acompanhamento. É importante sempre reforçar que os domínios são observados dentro das condições de cada pessoa. Além de auxiliar na avaliação de pessoas com outras condições médicas, a escala pode auxiliar na avaliação de aspectos específicos como ganho de auto-estima, auto-confiança, tópicos importantes para a promoção de bem estar e qualidade de vida. Alguns avaliadores relataram ainda que consideram ampla a aplicabilidade da Escala em processos musicoterapêuticos onde o terapeuta fornecerá as bases para acolher, manter, validar e estimular as respostas musicais expressivas e o engajamento do paciente, estreitando através disso o contato musical de modo significativo.

$\mathrm{Na}$ questão 14, quando perguntados sobre o formato original da escala, 7 avaliadores $(77,8 \%)$ consideraram adequado e 2 avaliadores (22,2\%) consideraram não adequado. Os que consideraram o formato original adequado descreveram que a formatação da escala original é de fácil preenchimento. Os que consideraram não adequado relataram que poderiam ser excluido alguns quadrados para melhor visualização.

Como a maior parte dos avaliadores considera adequado o formato original, optamos por mantê-lo, realizando apenas pequenas alterações sugeridas, como retirar alguns quadrados não preenchidos para facilitar o entendimento. Os quadrados não preenchidos não alteram o sentido da escala, pois foram desenvolvidos para que a escala fosse aplicada em vários atendimentos. Na Tabela 4 é possível observar o formato da "Escala de Musicabiilidade: Formas de Atividade, Estágios e Qualidades de Engajamento". 


\begin{tabular}{|c|c|c|}
\hline \multicolumn{3}{|c|}{ "Escala de Musicabilidade: Formas de Atividade, Estágios e Qualidades de Engajamento". } \\
\hline \multicolumn{3}{|c|}{ Formulários de Avaliação } \\
\hline \multicolumn{3}{|c|}{ Criança:____________ Data de Nascimento:__/__/__Data:__/__/___ Sessão:__/__/___ } \\
\hline Terapeuta:__-_-_ & Avaliador:_-_-_-_-_-_-_ & Data da Avaliação:__/__/__ \\
\hline
\end{tabular}

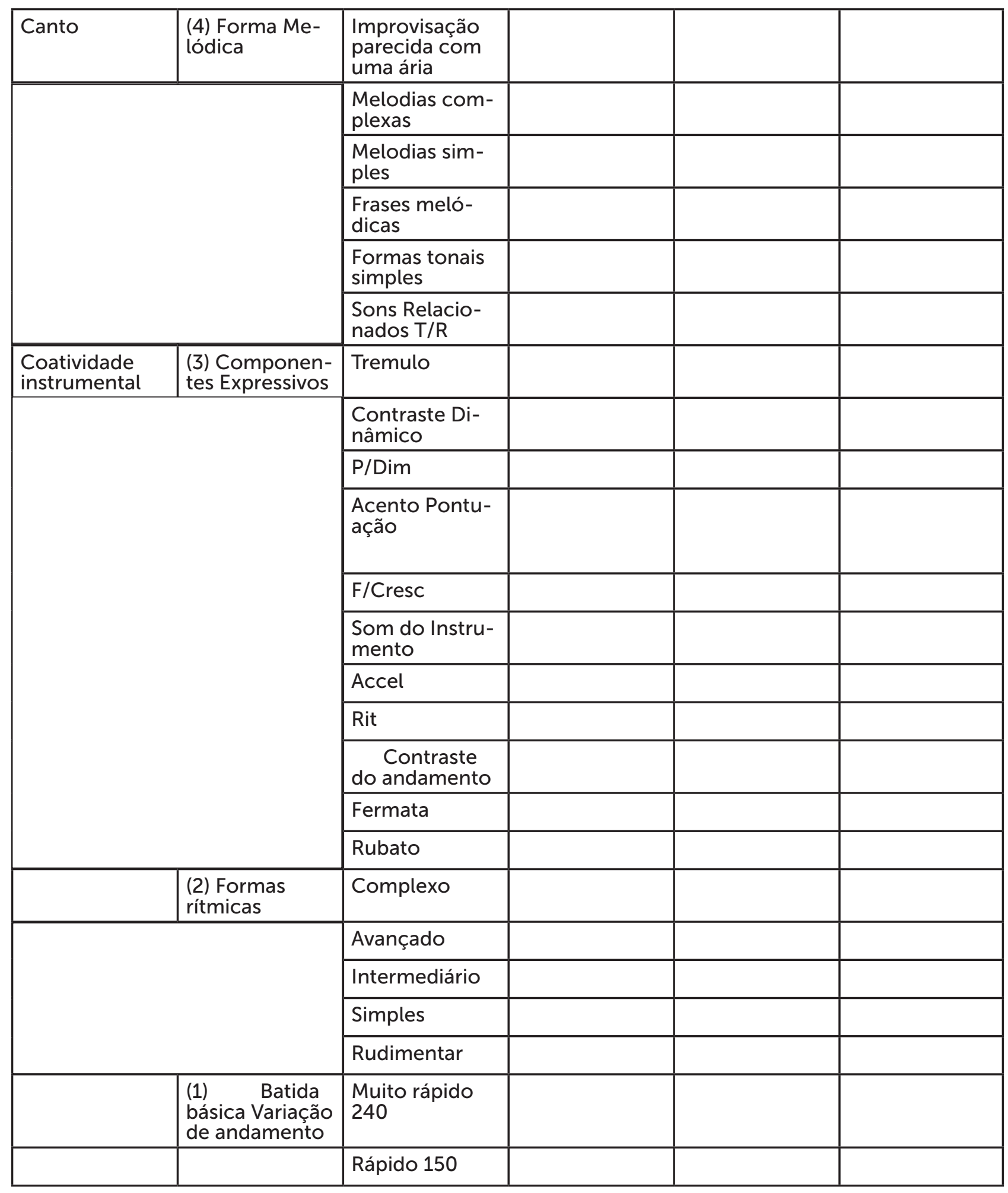




\begin{tabular}{|l|l|l|l|l|l|}
\hline & & Moderado 95 & & & \\
\hline & & Lento 60 & & & \\
\hline & & Muito lento & & & \\
\hline
\end{tabular}

Tab. 4: "Escala de Musicabilidade: Formas de Atividade, Estágios e Qualidades de Engajamento" questão 14.

Para classificar a qualidade de resposta do paciente, originalmente são realizadas marcações com siglas. Por exemplo, se o paciente emite sons vocais na sessão, o musicoterapeuta pode verificar se o mesmo é um som relacionado com algo no atendimento, se é um som tonal, se é uma frase melódica, se é uma melodia simples ou complexa ou se é um trecho de canção improvisada parecida com uma ária. Após identificar como é esse som emitido vocalmente, o musicoterapeuta pode registrar a fórmula de compasso no quadrado a frente na escala ou pode identificar como o paciente estava se comportando quando emitiu o som. As possibilidades para o canto descritas pelos autores são: Ativo não-responsivo (Responsively Active - A), Nascente (Nascent - N), Tornando-se engajado (Becoming Engaged - B), Assertivo de Forma Autoexpressiva (Self-Expressively Assertive - S) e Musicalmente Expressivo-Perceptivo (Musically Expressively Perceptive - M). No manual da escala estão descritos os significados das siglas e das palavras. Na Tabela 5 é possível observar as siglas originais e as respectivas palavras traduzidas.

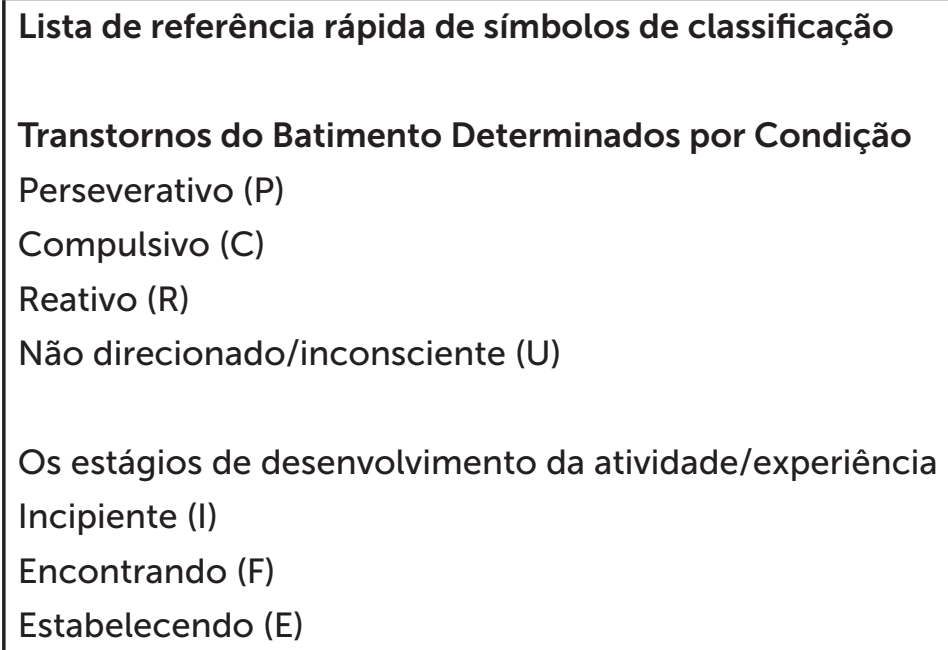

Tab. 5: Abreviaturas e palavras utilizadas para avaliação na "Escala de Musicabilidade: Formas de Atividade, Estágios e Qualidades de Engajamento". 
Na Tabela 6 é possível visualizar melhor a percentual de cada uma das respostas assinaladas pelos avaliadores.

\begin{tabular}{|c|c|}
\hline & do Questionário de Análise para Equivalências de Itens, Semântica e Ope \\
\hline & \\
\hline & $\begin{array}{l}\text { ando em consideração sua experiência profissional no contexto brasileiro, como você avalia } \\
\text { do geral os itens da "Escala de Musicabilidade: Formas de Atividade, Estágios e Qualidades de } \\
\text { mento"? }\end{array}$ \\
\hline • & Não pertinente $(11,1 \%)$ \\
\hline • & Parcialmente pertinente $(33,3 \%)$ \\
\hline$\bullet$ & Totalmente pertinente $(55,6 \%)$ \\
\hline & $\begin{array}{l}\text { no você avalia o domínio Coatividade instrumental na "Escala de Musicabilidade: Formas de } \\
\text { de, Estágios e Qualidades de Engajamento"? }\end{array}$ \\
\hline • & Parcialmente pertinente $(44,4 \%)$ \\
\hline$\bullet$ & Totalmente pertinente $(55,6 \%)$ \\
\hline & $\begin{array}{l}\text { no você avalia o domínio Canto na "Escala de Musicabilidade: Formas de Atividade, Estágios e } \\
\text { ades de Engajamento"? }\end{array}$ \\
\hline • & Não pertinente $(11,1 \%)$ \\
\hline • & Parcialmente pertinente $(11,1 \%)$ \\
\hline • & Totalmente pertinente $(77,8 \%)$ \\
\hline & $\begin{array}{l}\text { no você avalia a as classificações de andamento, formas rítmicas, componentes expressivos e } \\
\text { "melódicas na "Escala de Musicabilidade: Formas de Atividade, Estágios e Qualidades de Engaja- } \\
\text { "? }\end{array}$ \\
\hline • & Parcialmente pertinente $(33,3 \%)$ \\
\hline - & Totalmente pertinente $(66,7 \%)$ \\
\hline & $\begin{array}{l}\text { no você avalia a linguagem do manual da "Escala de Musicabilidade: Formas de Atividade, Está- } \\
\text { Qualidades de Engajamento"? }\end{array}$ \\
\hline - & Parcialmente compreensível $(55,5 \%)$ \\
\hline$\bullet$ & Totalmente compreensível $(44,4 \%)$ \\
\hline & $\begin{array}{l}\text { no você avalia a linguagem utilizada na "Escala de Musicabilidade: Formas de Atividade, Estágios } \\
\text { idades de Engajamento"? }\end{array}$ \\
\hline • & Parcialmente compreensível $(22,2 \%)$ \\
\hline • & Totalmente compreensível $(77,8 \%)$ \\
\hline & $\begin{array}{l}\text { considera que a "Escala de Musicabilidade: Formas de Atividade, Estágios e Qualidades de } \\
\text { ento" pode contribuir para a musicoterapia no contexto clínico brasileiro? }\end{array}$ \\
\hline • & $\operatorname{Sim}(100 \%)$ \\
\hline & $\begin{array}{l}\text { ê considera que a "Escala de Musicabilidade: Formas de Atividade, Estágios e Qualidades de } \\
\text { mento" pode contribuir para outras pesquisas brasileiras? }\end{array}$ \\
\hline & $\operatorname{Sim}(100 \%)$ \\
\hline & $\begin{array}{l}\text { cê considera a validação da "Escala de Musicabilidade: Formas de Atividade, Estágios e Qualida- } \\
\text { Engajamento" relevante para a musicoterapia no Brasil? }\end{array}$ \\
\hline • & $\operatorname{Sim}(100 \%)$ \\
\hline & $\begin{array}{l}\text { cê considera que a "Escala de Musicabilidade: Formas de Atividade, Estágios e Qualidades de } \\
\text { mento" pode auxiliar na avaliação de pessoas com atraso do desenvolvimento, também deno- } \\
\text { o transtornos do neurodesenvolvimento? }\end{array}$ \\
\hline$\bullet$ & $\operatorname{Sim}(100 \%)$ \\
\hline & $\begin{array}{l}\text { ê considera que a "Escala de Musicabilidade: Formas de Atividade, Estágios e Qualidades de } \\
\text { nento" pode auxiliar na avaliação de pessoas com outras condições médicas? }\end{array}$ \\
\hline - & $\operatorname{Sim}(100 \%)$ \\
\hline
\end{tabular}




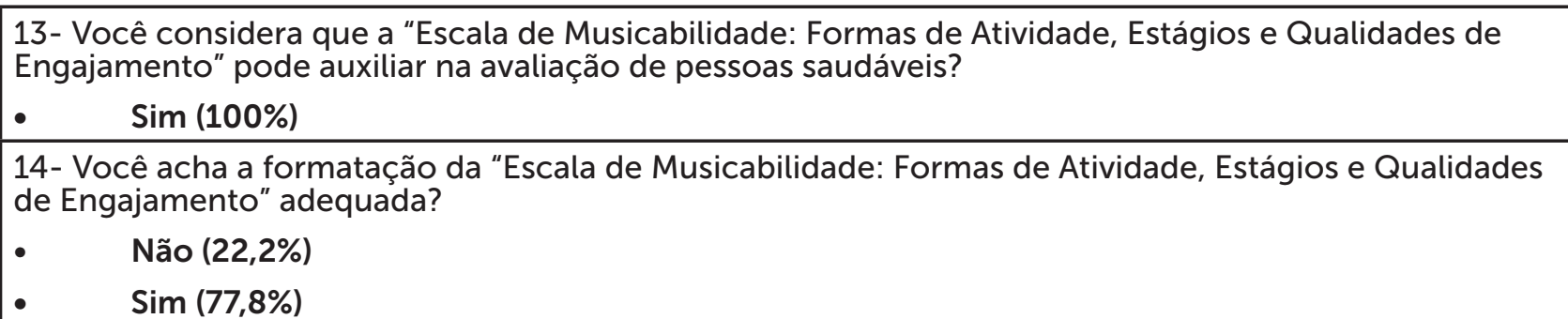

Tab. 6: Resposta do Questionário de Análise para Equivalências de Itens, Semântica e Operacional da "Escala de Musicabilidade: Formas de Atividade, Estágios e Qualidades de Engajamento".

\section{Considerações:}

Diversos autores como André (2017), André; Gomes e Loureiro (2019), Gattino et al. (2016), Gattino; Walter e Faccini (2010), Sampaio (2015) e Rosário (2015, 2019), relatam que no Brasil existem poucos instrumentos de avaliação que tenham sido estudados com objetivos de verificação de indícios de validade. O estudo atual com a "Escala de Musicabilidade: Formas de Atividade, Estágios e Qualidades de Engajamento" contribui para que mais instrumentos de avaliação estejam disponíveis para o uso musicoterapêutico no contexto brasileiro.

Através da análise das respostas dos avaliadores, é possível afirmar que a "Escala de Musicabilidade: Formas de Atividade, Estágios e Qualidades de Engajamento" pode ser considerada adequada em relação a semântica, itens e formato para o contexto musicoterapêutico brasileiro.

A maior parte dos avaliadores considera que a escala pode ser aplicada por um musicoterapeuta, mas é necessária uma leitura do manual para melhor entendimento dos conceitos inseridos. Embora alguns poucos avaliadores considerem que alguns musicoterapeutas possam não ter facilidade em lidar com alguns contextos musicais e não tenham no Brasil uma grande variedade de instrumentos musicais em todos os consultórios, acreditamos que a escala não depende de instrumentos musicais específicos para sua utilização. Com relação a formação do musicoterapeuta para lidar com conceitos musicais, como por exemplo conseguir definir caso um paciente cante um trecho de uma ária, acreditamos que embora não exista uma homogeneidade curricular, todos os cursos buscam capacitar o musicoterapeuta em questões teórico-musicais. Diversos autores, como Andre et al. (2015), Benenzon (1988), Bruscia (2000), Chagas e Pedro (2015), Cunha e Volpi (2008), Davis, Gfeller e Thaut (2008), Ruud (1990), Szweda (2015) e Thaut e Hoemberg (2014), relatam que o musicoterapeuta deve ter formação tanto em conhecimentos teórico-musicais quanto na prática instrumental. Com relação a linguagem do manual explicativo da "Escala de Musicabilidade: Formas de Atividade, Estágios e Qualidades de Engajamento", o mesmo seguiu a lógica e fluência do texto original em inglês. Possivelmente, por estar em uma linguagem literal houve certa dificuldade de alguns avaliadores no entendimento de alguns pontos do texto original. Contudo, é importante ressaltar que embora alguns avaliadores tenham considerado o texto do manual parcialmente pertinente, nenhum dos avaliadores considerou o texto 
não pertinente. Poderia ser interessante desenvolver uma versão mais curta em pesquisas futuras, a fim de possibilitar entendimento mais claro.

Com relação a sugestão dos avaliadores de retirar as siglas no manual, consideramos não ser possível, pois é importante que as mesmas continuem conforme são no idioma original. No entanto, consideramos que o avaliador pode optar por escrever a palavra inteira.

Embora o texto do manual não seja considerado totalmente claro, o texto da escala, foi considerado totalmente compreensível por maioria dos avaliadores, conforme vemos na resposta da questão 7. O texto da escala apresenta termos bastante utilizados na teoria musical como por exemplo: fermata, rubato, entre outros. Com relação ao formato da escala, o mesmo foi considerado adequado pelos avaliadores.

Todos os avaliadores concordam que além da escala ser relevante para a Musicoterapia brasileira e para futuras pesquisas, a mesma poderia ser utilizada para avaliação em diversas condições. Nordoff e Robbins (2007), autores dessa escala, descrevem que ela foi utilizada com êxito em diversas populações, como crianças com esquizofrenia infantil, transtorno emocional grave, lesão cerebral, deficiência visual, paralisia cerebral, deficiência mental grave e deficiência de aprendizado com complicações de afasia.

A "Escala de Musicabilidade: Formas de Atividade, Estágios e Qualidades de Engajamento" foi elaborada considerando princípios universais da música. Autores como Freire (2019), Kirkland (2013), Loureiro (2006) e Szweda (2015) relatam que a música está presente de maneira inata em todos indivíduos, independente de desafios, atrasos e deficiências que ele possa apresentar. Contudo, o modo como os indivíduos reagem a música pode demonstrar fatores culturais, emocionais e o seu estado de saúde (LOUREIRO, 2018; RUUD, 1991; THAUT, 2005).

Na Musicoterapia, diversos estudos estão sendo realizados mundialmente a fim de verificar meios de definir, quantificar e qualificar a musicalidade no atendimento clínico. Wosch e Wigram (2007) afirmam que é muito importante para a prática clínica ter a capacidade de perceber conscientemente e analisar criticamente a terapia, de forma a reagir adequadamente à pequenas mudanças sutis sociais, musicais, e comportamentais que podem ocorrer no contexto terapêutico. Para isso seria necessário realizar uma análise detalhada especificando mudanças mínimas que podem ocorrer nas interações entre o indivíduo, a música e o terapeuta.

Em próximos estudos, realizaremos análises estatísticas através da utilização da “Escala de Musicabilidade: Formas de Atividade, Estágios e Qualidades de Engajamento" na avaliação de comportamentos de pacientes que foram atendidos em sessões de Musicoterapia. Através da aplicabilidade da escala, seguindo o Modelo Universalista de Validação desenvolvido por Herdman, Fox-Hushby e Badia (1998), será possível verificar se a mesma apresentará as demais equivalências esperadas: equivalência de mensuração e equivalência funcional. Acreditamos que a "Escala de Musicabilidade: Formas de Atividade, Estágios e Qualidades de Engajamento" poderá contribuir consideravelmente com a avaliação musicoterapêutica no contexto brasileiro, pois a mesma descreve aspectos musicais presentes em muitos atendimentos de Musicoterapia. 


\section{Referências}

AMERICAN PSYCHIATRIC ASSOCIATION. Manual diagnóstico e estatístico de transtornos mentais DSM - 5. 5. ed. Porto Alegre: Artmed, 2014.

ANDRE, A. M. et al. Tecnologia e atraso do desenvolvimento: relações com a musicoterapia. 10 nas nuvens... congresso de música. Anais...10 Nas Nuvens... Congresso de Música, 2015

ANDRÉ, A. M. B. Tradução e validação da Escala Nordoff Robbins de Comunicabilidade Musical. Dissertação (Mestrado) - Universidade Federal de Minas Gerais, Minas Gerais, 2017.

ANDRÉ, A. M. B.; GOMES, C. M. A.; LOUREIRO, C. M. V. Estudo de revisão da utilização das Escalas Nordoff Robbins: "Relação Criança-Terapeuta na Experiência Musical Coativa" e "Musicabilidade: Formas de Atividade, Estágios e Qualidades de Engajamento". Revista Música (artigo em avaliação), 2020.

ANDRÉ, A. M. B.; GOMES, C. M. A.; LOUREIRO, C. M. V. Tradução e validação das Escalas Nordoff Robbins: "Relação criança terapeuta na experiência musical coativa" e "Musicabilidade, formas de atividade, estágios e qualidades de engajamento". (1, Ed.) XIV Simpósio Internacional de Cognição e Artes Musicais. Anais...Campo Grande: 2019

ANDRÉ, A. M.; GOMES, C. M. A.; LOUREIRO, C. M. V. Equivalência de itens, semântica e operacional da versão brasileira da Escala Nordoff Robbins de Comunicabilidade Musical. OPUS, v. 23, n. 2, p. 153, 2017.

BAKER, F.; ROTH, E. A. Neuroplasticity and functional recovery: Training models and compensatory strategies in music therapy. Nordic Journal of Music Therapy, v. 13, n. 1, p. $20-32,2004$.

BARCELLOS, L. R. Caderno de Musicoterapia, vol. 1Rio de JaneiroEnelivros, , 1992.

BENENZON, R. Teoria da musicoterapia. São Paulo: Grupo Editorial Summus, 1988.

BRUSCIA, K. Definindo musicoterapia. 2. ed. Rio de Janeiro: Enelivros, 2000.

CHAGAS, M.; PEDRO, R. Musicoterapia: desafios entre a modernidade e a contemporaneidade. 1. ed. Rio de Ja: Mauad Editora Ltda, 2015.

CRIPPS, C.; TSIRIS, G.; SPIRO, N. Outcome measures in music therapy: A resource developed by the Nordoff Robbins research team. 1. ed. London: Nordoff Robbins, 
2016.

CUNHA, R.; VOLPI, S. A prática da musicoterapia em diferentes áreas de atuação. Revista científica/FAP, v. 3, p. 85-97, 2008.

DAVIS, W. B.; GFELLER, K. E.; THAUT, M. H. An introduction to music therapy: Theory and practice. 3. ed. Matyland: ERIC, 2008.

FERREIRA, R. L. C.; TUPINÁ, P.; LOUREIRO, C. M. V. Musicoterapia da UFMG no atendimento a bebês prematuros de alto risco do Hospital Sofia Feldman. 4o Nas Nuvens... Congresso de Música: Anais (2018). Anais...2018

FREIRE, M. H. Estudos de musicoterapia improvisacional musicocentrada e desenvolvimento musical de crianças com autismo. Tese (Doutorado) - Universidade Federal de Minas Gerais, Minas Gerais, 2019.

GATTINO, G. S. Comunicação não verbal de crianças com Transtornos Do Espectro Autista : revisão sistemática e estudo de validação. Tese (Doutorado) - Universidade Federal do Rio Grande do Sul, Rio Grande do Sul, 2012.

GATTINO, G. S. et al. Tradução, adaptação transcultural e evidências de validade da Escalas Inprovisation Assessment Profiles (IAPs) para uso no Brasil: parte 1. Revista Brasileira de Musicoterapia, v. 20, n. XVIII, p. 92-116, 2016.

GATTINO, G. S.; WALTER, F. F.; FACCINI, L. S. Fundamentos sobre validade para o campo musicoterapêutico. (Associação Baiana de Musicoterapia, Ed.)X EMPEMT Encontro de pesquisa em musicoterapia. Anais...Salvador: 2010

HERDMAN, M.; FOX-RUSHBY, J.; BADIA, X. A model of equivalence in the cultural adaptation of HRQoL instruments: the universalist approach. Quality of life Research, v. 7, n. 4, p. 323-335, 1998.

KIRKLAND, K. International dictionary of music therapy. 1. ed. New York: Routledge, 2013.

LOUREIRO, C. M. V. Musicoterapia na educação musical especial de portadores de atraso do desenvolvimento leve e moderado na rede regular de ensino. Dissertação (Mestrado) - Universidade Federal de Minas Gerais, Minas Gerais, 2006.

LOUREIRO, C. M. V. Efeitos da musicoterapia na qualidade de vida visual de portadores de neurite óptica desmielinizante. Tese (Doutorado) - Universidade Federal de Minas Gerais, Minas Gerais, 2009.

LOUREIRO, C. M. V. Memória Musical Preservada na Demência Semântica: Um Estudo 
Preliminar. XXVIII Congresso da Associação Nacional de Pesquisa e Pós-Graduação em Música. Anais...Manaus: 2018

NORDOFF, P.; ROBBINS, C. Creative Music Therapy:Guide to Fostering Clinical Musicianship. 2. ed. New Hampshire: Barcelona Publishers, 2007.

ROSÁRIO, V. M. Desenvolvimento de um instrumento de avaliação da capacidade atencional em portadores de esclerose tuberosa através de princípios de atenção conjunta e de musicoterapia. Dissertação (Mestrado) - Universidade Federal de Minas Gerais, Minas Gerais, 2015.

ROSÁRIO, V. M. Proposição de uma metodologia para avaliação padronizada da atenção. Tese (Doutorado) - Universidade Federal de Minas Gerais, Minas Gerais, 2019.

RUUD, E. Caminhos da musicoterapia. 1. ed. São Paulo: Grupo Editorial Summus, 1990.

RUUD, E. Música e saúde. São Paulo: Grupo Editorial Summus, 1991.

SAMPAIO, R. T. Avaliação da Sincronia Rítmica em Crianças com Transtorno do Espectro do Autismo em Atendimento Musicoterapêutico. Tese (Doutorado) Universidade Federal de Minas Gerais, Minas Gerais, 2015.

\section{SILVA, A. M. DA. Tradução Para O Português Brasileiro E Validação Da Escala} Individualized Music Therapy Assessment Profile (Imtap) Para Uso No Brasil. Dissertação (Mestrado) - Universidade Federal do Rio Grande do Sul, Rio Grande do Sul, 2012.

SPIRO, N.; TSIRIS, G.; CRIPPS, C. A Systematic Review of Outcome Measures in Music Therapy. Music Therapy Perspectives, v. 36, n. 1, p. 67-78, 2017.

SZWEDA, S. K. The effectiveness and influence of Vocal and Instrumental Improvisation in Music Therapy on children diagnosed with autism. Pilot Study. The journal of Education Culture and Society, p. 153-166, 2015.

THAUT, M. H. Rhythm, music, and the brain: Scientific foundations and clinical applications. New York: Routledge, 2005. v. 7

THAUT, M. H.; HOEMBERG, V. Handbook of neurologic music therapy. England: Oxford University Press (UK), 2014. em: <http://www.wfmt.info/wfmt-new-home/about-wfmt/>. Acesso em: 25 out. 2015. 
WHEELER, B. L. Music Therapy Handbook. New York: Guilford Publications, 2015.

WOSCH, T.; WIGRAM, T. Microanalysis in music therapy: Methods, techniques and applications for clinicians, researchers, educators and students. 1. ed. London: Jessica Kingsley Publishers, 2007.

ZMITROWICZAB, J.; MOURA, R. Instrumento de avaliação em Musicoterapia: uma revisão. Revista Brasileira de Musicoterapia, v. XX, n. 24, p. 114-135, 2018. 